September -2009

\title{
Designing to Promote Access, Quality, and Student Support in an Advanced Certificate Programme for Rural Teachers in South Africa
}

\author{
Jill W. Fresen \\ Oxford University, UK \\ Johan Hendrikz \\ University of Pretoria, South Africa
}

\begin{abstract}
This paper reports on the re-design of the Advanced Certificate in Education (ACE) programme, which is offered by the University of Pretoria through distance education (DE) to teachers in rural South Africa. In 2007, a team re-designed the programme with the goal of promoting access, quality, and student support. The team included an independent body, the South African Institute of Distance Education (SAIDE), and various education specialists. Training workshops for academics and a comprehensive internal and external review process contributed to the quality of the re-designed programme. Interactive web-based technologies were not included because of poor Internet connectivity; however, the authors note the use and potential of cell phone technology for DE programmes. Student support was enhanced by an additional short contact session, a capping assignment, a CD-ROM, and decentralised tutoring at contact venues. The programme was re-evaluated and approved in 2008, and the re-design methodology now guides similar projects.
\end{abstract}

Keywords: Distance education; programme re-design; teacher education; materials development; electronic support; student engagement; exit level outcomes; learning outcomes; programme evaluation

\section{Advanced Certificate in Education Programme}

The University of Pretoria offers three distance education programmes in the Faculty of Education for teachers in rural areas. Due to the lack of access to technology, the primary delivery mode is paper-based learning materials. The Advanced Certificate in Education (ACE) (Education Management) programme underwent a major re-design endeavour for two reasons: to re-conceptualise the programme after five years of implementation in the normal course of continuous improvement as well as to address recommendations made by the national quality assurance agency, the Higher Education Quality Committee (HEQC). 
This paper reports on various strategies and methodologies that were adopted to ensure that the newly designed programme would meet not only the requirements of the HEQC but also international standards. The Unit for Distance Education at the University of Pretoria collaborated with the South African Institute of Distance Education (SAIDE), who presented workshops, facilitated the development of programme and module outcomes, and evaluated learning materials as they were being written. The Department for Education Innovation at the university provided services in terms of project management, educational consultation, graphic design, video production, and instructional design of a supplementary CD-ROM.

In a country like South Africa, where a large percentage of formal education takes place in deep rural areas, the up-grading and re-skilling of teachers are a real challenge. Teachers cannot attend universities in urban areas as residential students or take leave and stay away from home and school to attend lectures. An added challenge is that the recent Occupational Specific Dispensation (OSD) document of the Education Labour Relations Council (ELRC) determines that by 2013 all practising teachers must meet the M+4 level to be registered by the South African Council for Educators (SACE).

This requirement puts an extra burden on teachers to obtain at least an ACE qualification within the next five years. In view of the geographical position of many teachers, the only alternative delivery mode for such qualifications is by distance education. The purpose of this case study is to describe the process followed to develop an ACE specialising in Education Management. Various strategies were designed and implemented to produce a world-class qualification of high academic quality. Not only does the re-designed programme meet national needs, it also stimulates personal and professional growth of the teacher corps.

The authors of this paper are the project manager (one fifth of her time was allocated to this task), the full-time manager of the Unit for Distance Education, and the academic coordinator of the ACE programme (see the Team Approach section for a description of our responsibilities).

\section{Student Profile}

The ACE (Education Management) programme is targeted at practising teachers, experienced, fairly senior teachers as well as newly qualified or novice teachers. Analysis of the student profile reveals that these adult learners are geographically spread throughout South Africa, with the majority living in deep rural areas and teaching in schools that lack facilities such as functioning classrooms, libraries, and equipment. 

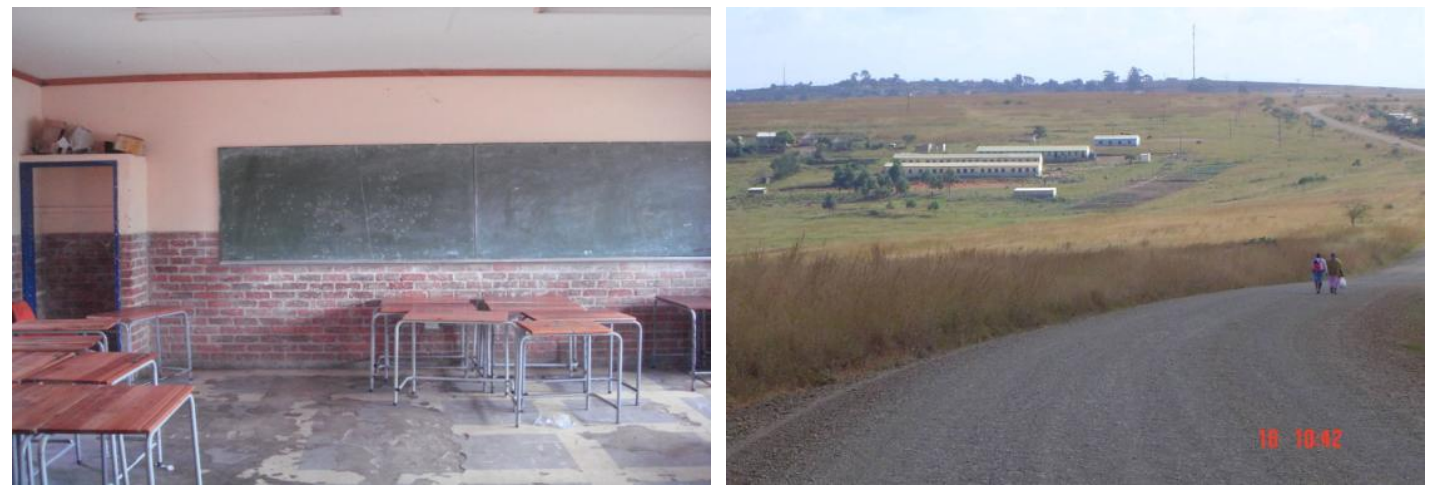

Figure 1. Disadvantaged schools in rural areas.

Demographic statistics reveal that all the candidates are in full-time employment as teachers: $70 \%$ are women, $61 \%$ are older than 40 years, and $90 \%$ are second language speakers of English. The proportion of students who have access to the Internet is very small (about 1\%). However, the number of students with access to a computer is growing significantly, from $9 \%$ in 2005 to $24 \%$ (almost one quarter) in 2007. In other words, the target population consists mostly of mature, female teachers, wishing to improve their qualifications, yet hampered by problems of distance, English literacy, and access to technology. Interestingly, almost all of them (99\%) have access to cell phones.

The ACE (Education Management) qualification empowers teachers to critically evaluate, develop, and improve self-management, classroom management, and the ability to contribute to the transformation of the school. Therefore candidates must be able to demonstrate applied competence, which includes foundational competence, practical competence, and reflexive competence. This was part of the underpinning philosophy of the re-design endeavour.

\section{Distance Education Model}

Distance learning programmes at the University of Pretoria operate within a customised, open, flexible learning academic model. A certificate programme offered by means of distance education consists of six modules (courses ${ }^{1}$ ), which must be completed within two to four years. The programme is sub-divided into three blocks of time (minimum of 6 months per block), with two modules (courses) per block. Students receive their learning materials in a staggered manner; that is, they receive the learning materials for two modules every six months. Students work at their own pace and cannot fail a year, only a module.

The University of Pretoria distance learning model is uniquely flexible in that students can enrol at any time of the year and write exams when they feel that they are sufficiently prepared. The only proviso is that they must finish the programme in the allotted maximum time by submitting two formative assessments and passing a summative assessment in each module. This provides students with unprecedented levels of flexibility and enables them to remain in the programme even when circumstances force them to cease studying for a while.

\footnotetext{
${ }^{1}$ In this paper the terms 'course' and 'module' are used synonymously.
} 


\section{Research Questions}

The following research questions guided the design and development process:

- What strategies should be used for the re-design and re-development of an existing advanced certificate distance education programme in order to promote access, quality, and student support?

- What processes should be followed in the re-design and re-development of the programme?

- What training is required to equip academic staff members to re-conceptualise their teaching and assessment strategies and to write effective learning materials?

- How can ICTs be incorporated in the re-designed programme to provide additional enrichment materials and electronic support to rural students?

Basically in reconceptualising a learning programme, one needs to consider the purpose of the programme, the structure of the programme, the articulation between modules in the programme, the learning activities, the support materials, and the assessment strategy. The South African Qualifications Authority (SAQA) provides the following diagram, which synthesizes all the concepts that should be addressed in the design of a learning programme.

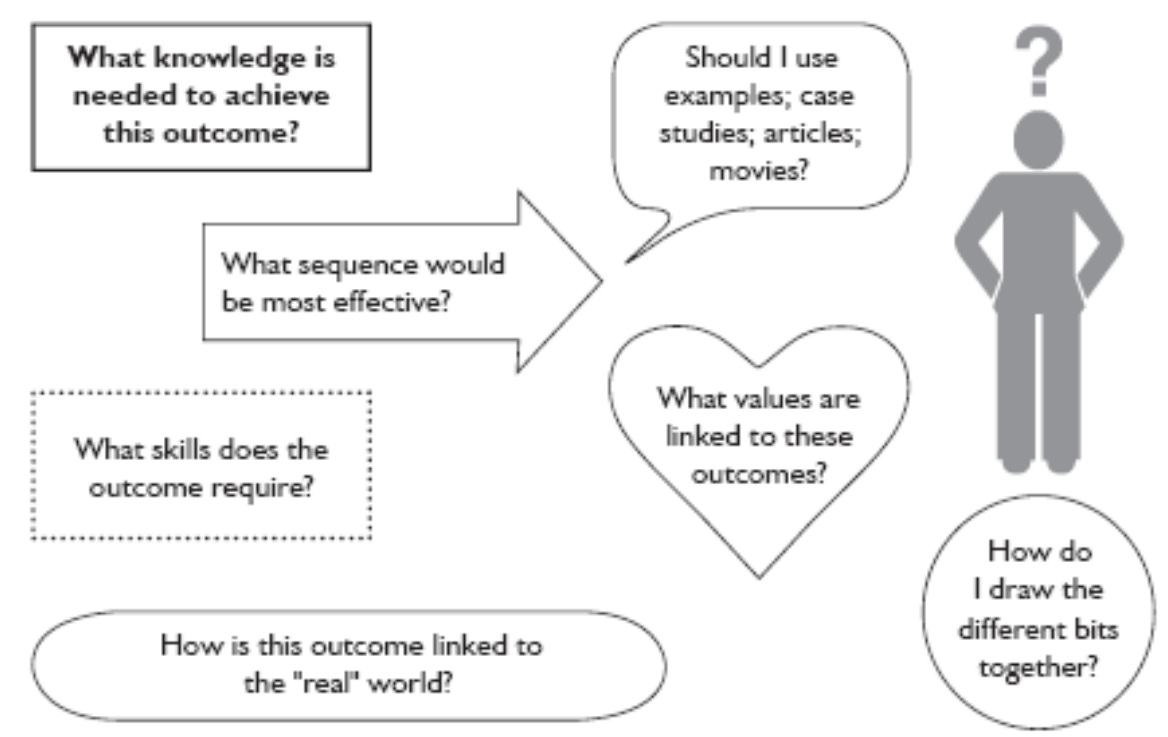

Figure 2. Designing a learning programme (Source: SAQA, 2005, p.4).

Figure 2 shows an informal and helpful synthesis of the kinds of questions an educator needs to consider in designing a learning programme: What do students need to know, do, and learn, and how may we design a learning pathway to assist them in achieving the required knowledge, skills, values, and outcomes? 


\section{Educational Approach}

The University of Pretoria is a contact institution. Hence lecturers are not trained in writing distance learning materials that are designed to promote learning for students at a distance. Furthermore, due to the lack of student access to the Internet, it was not feasible to consider online facilitation, interaction, and communication. It was necessary to engage the lecturers in thinking about how to promote student learning by means of paper-based distance education and limited contact sessions.

A paradigm shift was required, from the content transmission approach to a more reflective, Socratic approach. The authors of the materials (the lecturers) needed to realise that in the faceto-face situation, it is easy for the lecturer to 'get a feel' for whether the students are engaged, to respond to their questions immediately, and to guide and structure the lecture in a way that addresses their needs at particular moments. As far back as 1990, Beaudoin (1990) pointed to a dramatic evolution in the roles of lecturers in terms of how to contribute to the teaching and learning process of independent, distributed students - a process which involves learning rather than teaching. In distance education in particular the writer needs to anticipate what a learner is likely to think or do. One of the key mechanisms to achieve this process of anticipation and reflection is to construct meaningful and relevant learning activities to guide the learner along a learning pathway (Moll \& Drew, 2008). Learners need to be invited to reflect on what they have read and on their own experiences, to discuss issues with their colleagues and peers, to practice certain skills, and to consult resource materials for further information and practice (Smythe \& Witthaus, 1998).

The aim was to produce a comprehensive yet coherent curriculum. One of the recommendations of the HEQC was that the content, activities, and assessment should be integrated across the entire programme. This required another paradigm shift - for the module writers to be more in touch with each other, and to work together throughout the process. The dilemma was to ensure that the modules 'speak to' each other and build upon each other, without unnecessary repetition. It was not easy to solve this dilemma in an elegant way. The best that the management team could do was to encourage the module coordinators and writers to meet regularly, to review each others' materials instead of writing in isolation, and to seek instances where cross referencing between modules was meaningful.

\section{Methodology}

This section presents the research design, the improvement plan, the methods adopted (team approach and workshops), and the process that was followed.

\section{Research Design}

It was decided to adopt the "Design Down $\rightarrow$ Deliver Up" methodology (SAQA, 2005), which

was conceptualised by SAQA as a step-by-step approach to developing learning programmes 
based on outcomes. Figure 3 illustrates the methodology, which can be applied both at the level of a programme (exit level outcomes) and a course (specific learning outcomes). The methodology was developed in order to meet the need of "providers [who] are faced with the responsibility of planning the learning and assessment processes that support the achievement of outcomes and enable the quality assurance of such achievement" (SAQA, 2005, p. 1). A learning programme is defined as the "learning and assessment activities derived from the outcomes that make up a qualification. This is what the provider designs, based on sound educational principles (for example, learner centeredness)" (SAQA, 2005, p.1).

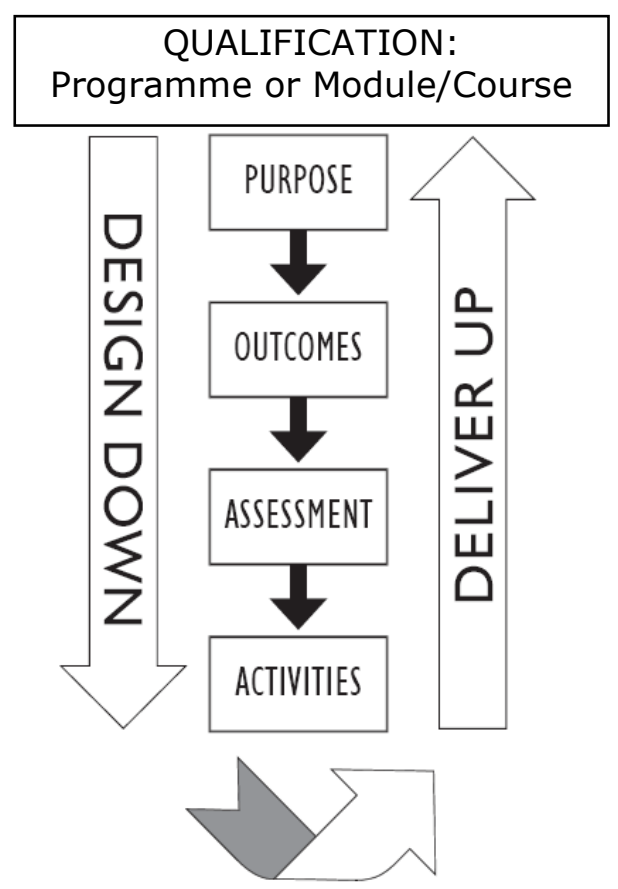

Figure 3. The "Design Down $\rightarrow$ Deliver Up" approach (Source: Adapted from SAQA, 2005, p.6)

Starting from defining the purpose of the learning programme, the methodology moves down to specify how the purpose can be achieved, or, in other words, what learning outcomes will need to be achieved, including knowledge, skills, attitudes, and values. The next step is to design an assessment strategy in order to be able to know if the students have achieved the outcomes. However, we cannot simply make learning material available to students and expect them to be ready for assessment; we need to plan and design learning activities to guide students along the learning pathway and to prepare them for the assessment.

Once the design down process is complete, you will 'deliver up', that is, conduct learning activities which will prepare your students for the assessment activities. These in turn will provide evidence that they have met the outcomes and thereby achieved the purpose of the qualification. (SAQA, 2005, p. 6) 


\section{Improvement Plan}

Two broad key priorities were identified, which formed the basis of the improvement plan:

- re-design of the learning programme, i.e., purpose, educational approach, assessment strategy, materials development;

- improvement of academic student support, i.e., support systems to facilitate and enhance the learning of students.

The particular components shown in Figure 4 are discussed below the figure.
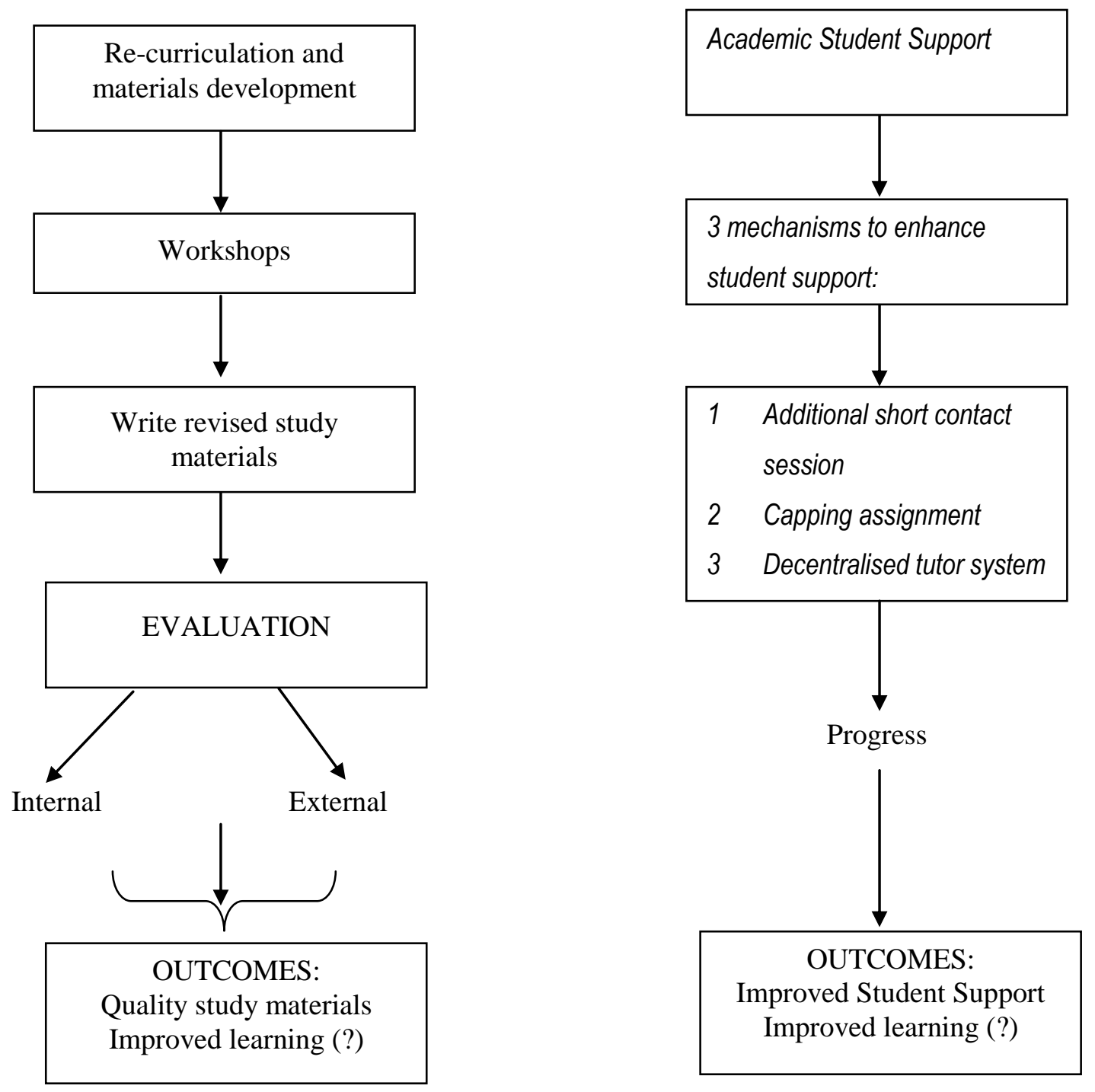

Figure 4. Improvement plan for the re-design of the Advanced Certificate in Education (ACE) programme (Source: Van der Bank, 2008). 
These main priority areas of improvement entailed the following issues:

- revisiting the academic cycle;

- reviewing and clarifying the underpinning theory of the programme;

- reviewing roles and responsibilities of the academic staff (programme and module coordinators);

- additional resources to enhance student learning in the form of a CD-ROM and access to UP library resources;

- additional academic student support in the form of an extra short contact session (2 days) and a capping assignment; and

- a decentralised tutor system to facilitate student learning.

The main priorities of the re-design exercise were fundamental issues such as the theoretical underpinning and the purpose of the programme.

\section{Team Approach}

From the beginning it was decided to contract the South African Institute for Distance Education (SAIDE), a non-governmental organisation, to facilitate the process, to ensure that national policies and requirements were adhered to, and to assure the quality of the programme design and the learning materials.

A team approach was adopted in order to ensure that sufficient experts and resources were allocated to the project. The team consisted of the following specialists:

- Manager: Unit for Distance Education, Faculty of Education,

Overall responsibility for management, coordination, and administration of distance education programmes;

- Academic coordinator: Distance education programmes, Faculty of Education, Responsible for the quality of the academic content and standard of the programmes;

- Distance education consultant: South African Institute for Distance Education (SAIDE), A consultant in distance education and the design and development of programmes and learning material, bearing in mind national legislation, and a reviewer of learning materials;

- Project manager: Department for Education Innovation (support department), Overall coordinator of the production and evaluation of learning materials, managing the timeline and deliverables, reviewing learning materials and producing progress reports;

- Programme coordinator: Department of Education Management (academic department), Coordinator of the process followed by module writers and co-writers, reviewer of learning materials, and point of contact for all role players;

- Authors and co-writers per module: Department of Education Management, Subject matter experts who wrote the learning guides, provided reading lists for the CDROM, and facilitated contact sessions; 
- Education specialist: Department for Education Innovation (support department), Pedagogical expert who reviewed materials in terms of alignment of learning outcomes and activities and implementation of the workshop outputs;

- Language editor (external contractor)

English language editing to ensure consistency and accuracy of learning guides and tutorial letters;

- Library information specialist: Department of Library Services, Procurement of copyright permission and building e-library pages in HTML for the CDROM;

- Instructional designer, graphic artist, photographer, video producer: Department for Education Innovation,

Design and development of the visual and audio material on the CD-ROM, icons used in learning guides, art work for learning guides, CD-ROM, and marketing materials;

- Desktop publishing (DTP) expert,

Professional layout of paper-based learning guides;

- Printers,

Printing and production of paper-based learning guides and tutorial letter booklets.

Further support personnel are engaged, as necessary, in the normal course of the programme, such as academic supporters, facilitators of contact sessions, tutors and markers, but these role players were not involved directly in the re-design process.

\section{Workshops}

The first issue that urgently needed attention before study materials could be re-designed was the underpinning theory, which is fundamental to this programme. This is closely linked to the purpose of the programme as well as the target group for whom the programme was to be developed. SAIDE facilitated three inter-related workshops, all of which were based on the Design Down $\rightarrow$ Deliver Up approach. The workshops took place during April and May 2007 and were structured as follows: workshop 1 focused on the overall programme design including the academic cycle; workshop 2 focused on programme specific curriculum design, concentrating on the relationship between content, outcomes, and assessment strategy; workshop 3 focused on capacity building in terms of materials development.

SAIDE accepted responsibility for the following three aspects:

- working in close cooperation with the programme coordinator and module coordinators on the curriculum and learning design for the six ACE (EM) modules;

- working with the Department for Education Innovation to develop a template for the writing and preparation of the study materials;

- keeping standards and quality of the materials on a high level and alerting the university in a timely manner if this was not the case. 
The workshops produced useful outputs. At the programme level, the structure of the programme was formulated, together with its purpose and the desired exit level outcomes. It was clearly indicated how individual modules address the exit level outcomes and integrate with each other. At the module level, outlines were developed for each of the six modules according to a template, which describes the purpose of the module, links with other modules, learning outcomes, key assessment tasks, and associated assessment criteria for each unit within a module. The third output from the workshops was the beginning of a programme overview document, which evolved as writers prepared materials and was refined into a useful guide provided to all new students entering the programme.

\section{Process of Materials Writing}

The process was a complex one, considering all the team members involved and the extent of the peer and expert evaluation that was agreed upon (see Evaluation). In order to ensure that the writing of materials did not proceed too far without peer evaluation, it was decided to divide the materials development process into three phases:

- phase 1 - produce the introduction to the module and write materials and activities for unit 1 ;

- phase 2 - complete writing of materials and activities for the first half of the module;

- phase 3 - complete writing of materials and activities for the rest of the module.

After the workshops, and working from their module outlines, each author and their co-writers began writing their learning guide ${ }^{2}$ and compiling a list of required readings for their Reader $^{3}$ (if required). The due dates for phases 1, 2, and 3 were mid-June, mid-July, and mid-August, 2007, respectively. On completion of each phase, the material was internally evaluated and then evaluated by SAIDE (see Evaluation section). After phase three, each complete module was evaluated internally, externally by SAIDE, and then by two critical readers in the field. Language editing was also carried out after the completion of each learning guide.

The implication of this process, so closely interwoven with evaluation, was that after each phase, the materials with comments were returned to the authors (lecturers) for their attention. This was a significant burden for lecturers who had to deal with responding to the comments and queries over and above their usual workload and sometimes in a time span as short as one weekend. The challenge was addressed by forewarning the lecturers in plenty of time and sharing with them the process flowcharts so that they understood the complexity of the demands and time pressures placed on all role players. Fortunately they appreciated the strategic importance of the curriculum re-design project since the academic programme had been discontinued by the HEQC until the

2 The term 'learning guide' was agreed upon, as opposed to 'study guide', 'learning manual', 'study manual' or similar.

${ }^{3}$ It was decided not to use any prescribed text books, but to provide additional content in the form of a paper-based reader, if required. This was the case in three of the six modules. The remaining modules presented all the required material in the learning guide. 
newly designed programme became available. Most lecturers were able to meet the tight deadlines, even if it meant contracting part-time secretarial help. A saving grace was that other service providers, such as the language editor and the printing house, could not cope with all six modules at once, so delivery times could be staggered. The process was managed from the project management point of view by means of tables, schedules, and flowcharts built in MS Excel.

\section{Evaluation: Internal, External, National, and International}

Credible and rigorous review mechanisms are critical in order to ensure the quality of programme design as a whole, as well as learning materials. Woodley and Kirkwood (1998) confirm that, "The primary aim of evaluating instruction is to improve the quality and effectiveness of the teaching and learning involved ... there is the potential to improve not only individual teaching materials, but also the overall course of instruction" (p. 291). Informal, formative evaluation may be conducted by asking colleagues or education experts to peer review learning materials. External critical readers who are experts in the subject area may be commissioned to formally review and comment on draft materials (Woodley \& Kirkwood, 1998).

In this case study, internal, external, national, and international review arrangements were made, as discussed below. Figure 5 summarises the role players who were involved in reviewing the programme and the materials at the course level. An evaluation checklist was drawn up, based on nationally accepted quality criteria (Welsh \& Reed, 2005). The checklist was used by the internal reviewers and the critical readers.

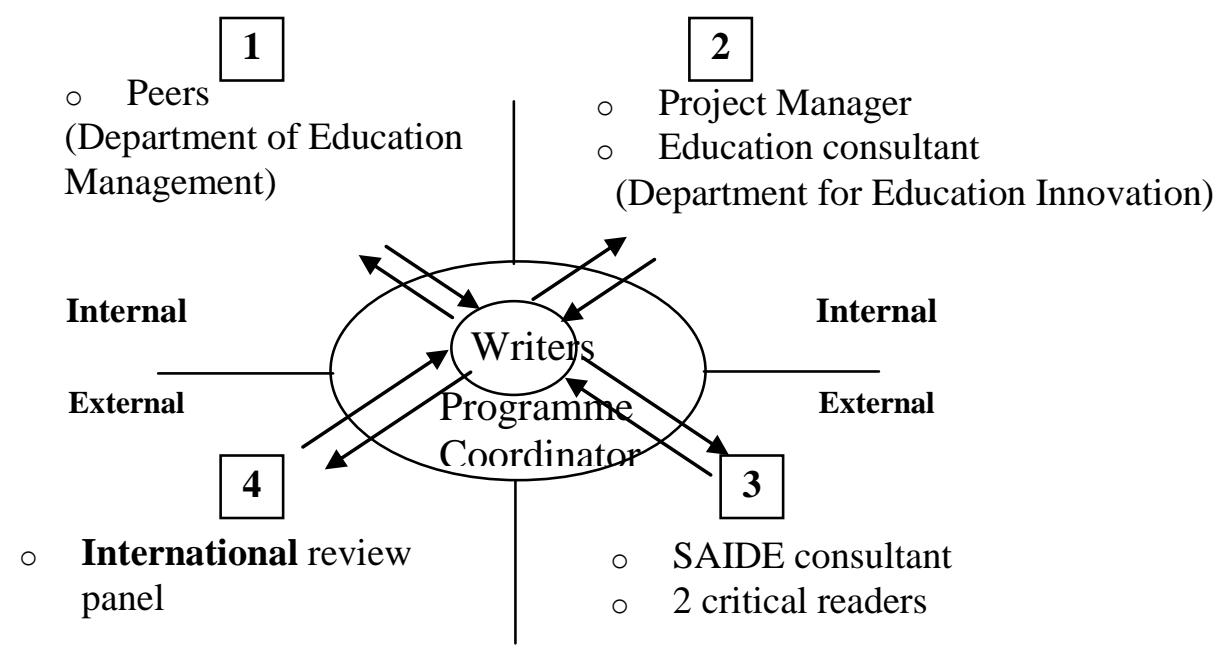

Figure 5. Evaluators involved in assuring the quality of the programme and the learning materials

After each stage of the evaluation process, the materials were returned to the writers in order to address the comments and changes suggested by the reviewers, which resulted in a cyclical, iterative process of continuous improvement. The timeline was planned such that for all six modules, the internal reviews (stages 1 and 2 in Figure 5) took one, two, and three weeks respectively for phase 1 (introduction and unit 1), phase 2 (first half of the units), and phase 3 (the 
complete modules). The external SAIDE consultant (stage 3 in Figure 5) similarly took one, two, and three weeks respectively to evaluate modules in phases 1,2 , and 3, which took the project to early October 2007. An array of suitably qualified critical readers had been previously identified and contracted. They were each given 10 days to evaluate one module and write their report.

The language editing activity caused a delay, since one highly recommended language editor had been contracted to edit six modules, for which she required six weeks. By early December 2007, the entire programme was ready to go to the international review panel, which produced a report by mid-January 2008. Due to the rigorous nature of the review cycle, the extent of edits required by the international panel was minimal. The materials then went for desktop publishing and printing during February and were ready for despatch to students in March 2008. The entire exercise, from initial workshops to a set of quality assured learning materials, had taken exactly one calendar year.

\section{Internal Reviews}

An internal review and evaluation process on the completed study material was followed to ensure that the content was relevant and that the standard and language register of the materials met the required criteria. The internal reviews were conducted by the programme coordinator, the project manager, and the education consultant. The authors had to make changes and address comments before the next step in the review process started.

\section{External National Review}

Two critical readers were appointed for each module. Each of the critical readers received a checklist according to which the study material should be reviewed based on the accepted assessment criteria. The reports of the critical readers were studied carefully and the necessary recommended changes were made by the authors.

\section{External International Review}

In order to ensure that the programme not only met national standards and requirements but would also meet international requirements, the programme (all modules and additional information) was submitted to an international team of reviewers, coordinated by a well-known international expert on distance education study materials and delivery modes. The international panel produced a report in which the programme was commended and the University was congratulated on the quality thereof. 


\section{Use of ICTs}

The University of Pretoria firmly believes that, to be in the forefront of knowledge creation, management, and dissemination, high quality, efficient educational provision should encompass the optimal use of technology. Innovation and flexibility within a learning environment should not only be permitted but encouraged.

\section{CD-ROM}

Rich environments are known to engage students in terms of active learning and authentic contexts (Grabinger \& Dunlop, 1995). Attention was given to the importance of real-life learning activities as well as the need for a more resource-rich environment, which had been identified by the HEQC. A "push technology" approach was adopted, notwithstanding the knowledge that only a quarter of the students have access to computers. The intention of this strategy is to encourage students to try to get access to a computer, either at the schools where they work or at an Internet café. Other development initiatives in the country, such as the Digital Doorway project (Meraka Institute, n.d.), are involved in bringing computer facilities to rural areas.

A CD-ROM was developed for the ACE students in order to provide additional electronic supporting resources. The team was careful to ensure that the CD-ROM contains enrichment learning materials and not compulsory reading, so the majority of students, who do not have access to computers, are not disadvantaged in any way. The optional extra materials on the CDROM include an "e-library" (library articles), generic academic support (e.g. study skills, time management, coping with stress, etc.), video clips to demonstrate the completion of administrative documentation, and a photo gallery of the campus of the University.

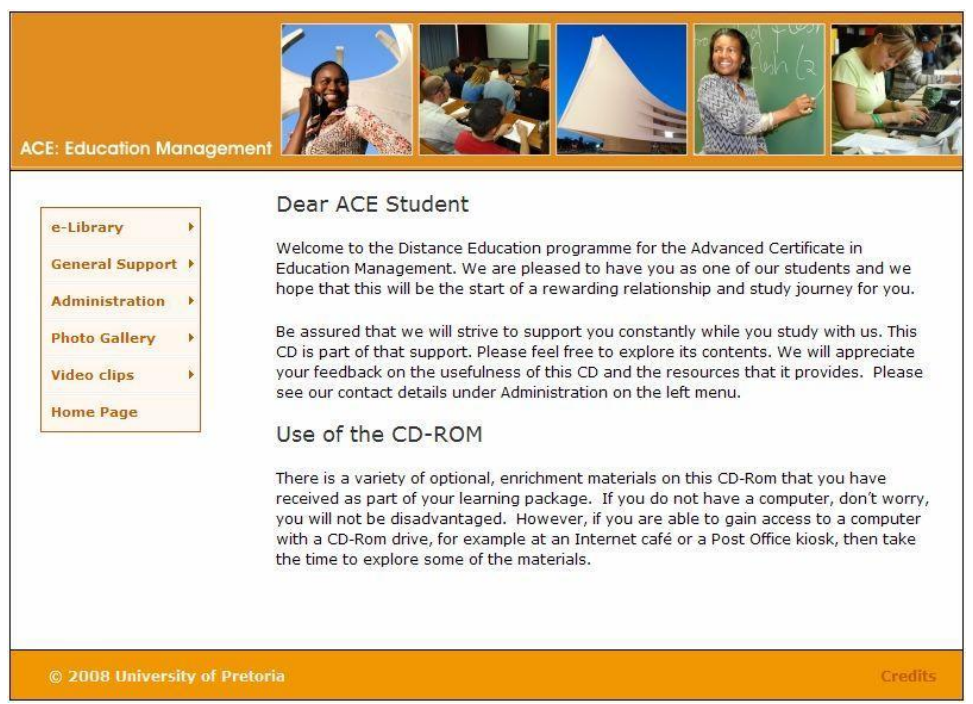

Figure 6. Home page of the supporting CD-ROM. 


\section{Microsoft Word Template}

SAIDE suggested the development of a Microsoft Word template for authors to use in order to yield greater alignment in terms of layout, fonts, heading styles, etc. The Department for Education Innovation built such a template and trained the lecturers how to use it in a two-hour hands-on computer session. Guidelines were provided in the form of Guidelines for Writers (house style, use of language, referencing style etc.) as well as Technical Guidelines (MS Word technicalities such as generating an automatic table of contents, the use of electronic comments, page layout, etc.).

Although all the lecturers used the template, they did so with varying degrees of success, due to their varying levels of computer skills and experience. It appeared that their thinking about the content was not constrained by the use of the template; indeed, it prompted them to try to make the materials more interactive by using activities and feedback, instead of lapsing into a transmission approach. The outcome was that it saved considerable time in the final stages of formatting the learning guides and was certainly preferable to working without any sort of formatting structure.

\section{Cell Phone Technology}

Cell phone technology (m-learning) is utilised to support distance education students. Although only $1-2 \%$ of distance education students have regular access to an Internet-enabled computer, more than $99 \%$ of them have cell phones. The university is committed to making use of bulk SMSs (text messages) to communicate important administrative issues to students as well as to use m-learning (mobile learning supported by cell phone technology) for academic purposes. Five types of SMS interactions are used to support distance students: academic instructional messages to students, interactive quiz questions with feedback provided, submission from students of answers to paper-based quizzes, academically relevant questions from students, and 30-second mini lectures on important concepts. The valuable opportunities provided by mobile learning in this unique context and how they are being used for this target population are the subject of a different article (Hendrikz \& Prins, 2009).

\section{Student Support Mechanisms}

One of the priorities of the improvement plan (see Figure 4) was to develop and implement strategies to improve and enhance academic student support and student learning. UP distance education students may attend various centres around the country for face-to-face contact sessions with full-time academic staff as well as with specially employed, trained, and monitored tutors. A well-defined research project, headed by a permanent researcher, has since been established to investigate the effectiveness of all the student support mechanisms described below. 


\section{Additional Short Contact Session}

In the past, students attended a "long" contact session (4 days) every six months, which was well into the semester. This project introduced an additional "short" contact session ( 1 day) at the beginning of the programme. The purpose of this additional contact session is threefold:

- student orientation and comprehensive clarification of all administrative issues;

- introduction to generic academic issues to prepare the student for his/her study and learning journey, including issues such as study methods, how to analyse and answer questions, critical reflection skills, academic writing (how to develop an argument);

- orientation for modules in the different blocks - what is expected from the student.

Feedback from students after the session held in April 2008 was positive and will contribute to determining the effectiveness of such an orientation contact session to promote the success of students who have not studied for a long period of time.

\section{Capping Assignment}

The capping assignment is an integrated assessment exercise to be submitted after all the modules have been passed. The purpose of this overall assignment is to ensure that students are able to integrate what they have learnt in all the modules in the programme. It is designed to help them to apply this integrated knowledge in the practical school situation and to think holistically in order to be successful in their teaching practice. This assignment will also help the design team to determine the impact of the programme, i.e., whether the programme overall is achieving its purpose. The first submission of the capping assignment will take place later in 2008. The evaluation of its effectiveness provides scope for further research.

\section{Decentralised Tutor System}

This system is an effort to assist students in their learning process by means of regular tutorials where appointed tutors facilitate sessions with students. Tutors at the 15 contact session venues have been trained on techniques in facilitating learning. The tutorial sessions were quality assured by a team of quality assessors (mainly module coordinators and academic supporters). Two of the four annual tutorial sessions have taken place so far. Feedback from students as well as from the tutors has been positive. Feedback is utilised to improve the tutorial sessions and in particular the learning facilitation process.

\section{Challenges and Lessons Learnt}

In pursuing various strategies and methods to adopt in the re-design of the ACE (Education Management) certificate, a number of challenges were encountered and lessons were learnt. The majority of challenges were well-known and concerned the characteristics of the student population: they live in rural areas, they cannot afford to take time off work to attend regular 
classes, and they lack access to Internet technology. The entire academic model of the Unit for Distance Education has been sensitive to these constraints since its inception in 2002. Clearly in the circumstances, all required learning materials had to be produced in paper format and mailed to the students, and online Internet-based learning was inappropriate. In order to introduce some enrichment in the form of electronic support, the CD-ROM provided an optional e-library and academic support materials for the growing number of students who at least have some form of access to a stand-alone computer. A unique opportunity presented itself in the prevalence of mobile phone ownership, which has been exploited in innovative ways including administrative message and academic support to remote students (Hendrikz \& Prins, 2009).

A valuable lesson that we learnt was to involve the independent body, the South African Institute of Distance Education (SAIDE), in the entire re-design and materials development exercise in order to ensure that the redesigned programme meets the standards of national quality assurance bodies. Further, the use of independent critical readers in the field and an international review panel ensured that the programme meets recognised national and international academic standards.

The cost implications of the re-design effort were significant, not least the replacement of the entire package of learning materials that were still in circulation (over 5,000 enrolled students). The cost of producing 7,000 CD-ROMs amounted to ZAR 85,000, while the fees to SAIDE, the critical readers, and the international review panel were also significant. Fortunately the Unit for Distance Education is in a position to carry such costs, due in large part to the significant income that distance education students contribute to the university.

In any curriculum re-design attempt, the implications in terms of human resource demands should not be underestimated. In this case study, it was a wise decision to commission sufficient team members to provide required support in the form of project management, educational consultation, graphic design, language editing, and design and development of learning materials. Another challenge was the vagaries of the academic environment, implying that academic staff members value their independence and are unused to enforced deadlines such as might be commonplace in a commercially critical endeavour. The project team had to be sensitive to the demands on academic colleagues and flexible in circumventing delays even if this meant going beyond the call of duty, such as collecting materials from lecturers and delivering them to printers after normal office hours. Nevertheless, the load on the lecturers and their co-writers was significant, not only in terms of designing and developing the learning materials in their subject area but also in getting to grips with technical layout and formatting requirements. Even though they realised the strategic and moral importance of the curriculum re-design project, there was some resistance and some delayed deliverables. In future, incentives for lecturers are recommended, such as time off from regular duties, secretarial assistance, and perhaps even funding to attend distance education conferences, or to buy technology such as laptop computers and mobile devices for learning.

The re-design exercise took an entire calendar year, which was longer than what had been hoped. As delays were encountered, milestones along the timeline had to be adjusted and service 
providers further along the timeline (such as language editor, printers etc.) had to be forewarned as to the shrinking time available. Fortunately this strategy, as well as the willingness of all concerned to produce under pressure, meant that the newly-designed programme was ready for students by April 2008.

\section{Conclusion}

The value of mapping learning outcomes to module content is confirmed by Ganor (quoted by Holmberg, 2005): "Specification of course content and its instructional objectives in 'course maps' serve as a basis for preparing a teaching syllabus" (p. 125). In this curriculum re-design project, the value of the various mapping exercises and mapping documents was that the silo nature which had characterised the previous programme (both across and within modules) was successfully demolished. This had been a strong recommendation by the Higher Education Quality Committee (HEQC) when they evaluated the previous programme.

In reflecting on the answers to the initial research questions, the team came to the conclusion that the methodology adopted had been successful in addressing not only the recommendations of the HEQC but also the moral imperative of providing a world-class distance education programme for rural teachers. The first two questions about strategies and processes for the re-design and redevelopment of an existing advanced certificate were answered by the Design Down $\rightarrow$ Deliver Up methodology (SAQA, 2005) that was adopted. The preparatory workshops and the cyclical nature of the comprehensive internal and external review process have informed and will continue to inform similar curriculum design projects at the University of Pretoria and conceivably at other institutions.

The third research question was about the level of training required to equip academic staff members not trained specifically in the field of distance education to adapt their teaching strategies and to write effective distance education learning materials. In this regard, the workshops facilitated by the South African Institute of Distance Education (SAIDE) and their involvement in the first stage of external review of the materials were invaluable. The professional development opportunity for academic staff members has carried over into their thinking about their contact programmes, their learning outcomes and learning activities, and their assessment strategies.

The fourth research question investigated how information and communication technologies (ICTs) might be incorporated in a distance education programme to provide additional enrichment materials and electronic support to rural students. Due to the particular challenge of the lack of access to the Internet, it was clear from the start that interactive web-based technologies were not applicable. The $25 \%$ of students who do have access to computers meant that they could at least access optional enrichment materials on a CD-ROM, without disadvantaging the majority. In this way, the CD-ROM has encouraged more students to seek computer access, but it is too early to evaluate its effect on learning. A unique opportunity exists in terms of the use of mobile phones for both administrative and academic interaction with students, which is presented elsewhere (Hendrikz \& Prins, 2009). 
The team of academics, co-writers, internal and external evaluators, project manager, and Distance Education manager emerged from the experience convinced that the effort and time commitment had been worth it. The newly designed Advanced Certificate (Education Management) programme was re-evaluated by the HEQC team in February 2008 and was approved without question. The same methodology has since been implemented with a different team of academics to re-design the curricula and learning materials for the other two distance education programmes offered to rural teachers.

The new student support mechanisms, such as additional short contact session, CD-ROM, and tutorial sessions, are still in the process of implementation and evaluation. Comprehensive feedback processes and various action research projects are in place to determine the success and effectiveness of these support mechanisms, which will provide the basis for future studies. 


\section{References}

Beaudoin, M. (1990). The instructor's changing role in distance education. The American Journal of Distance Education, 4(2), 21-29.

Fresen, J.W., Van der Bank, A.J., \& Hendrikz, J. (2008, June). Re-curriculation of an advanced certificate programme for distance education. Paper presented at the Education Innovation (Eduvate) Conference - Education Innovation Quest: A Century in the Service of Knowledge, University of Pretoria, Pretoria, South Africa.

Grabinger, R.S., \& Dunlop, J.C. (1995). Rich environments for active learning: A definition. Alt$J$ 3(2), 5-34.

Hendrikz, J., \& Prins, G. (2009). The use of mobile phones in enhancing academic performance in distance education: An African perspective. To appear in the Conference Proceedings of the International Council for Open and Distance Education (ICDE), June 2009.

Holmberg, B. (2005). The evolution, principles and practices of distance education. In U. Bernath, F.W. Busch, D. Garz, A. Hanft, \& W-D. Scholz (Eds.), The evolution, principles and practices of distance education. Vol. 11. Oldenburg: Bibliotheks-und Informationssystem der Universität Oldenburg.

Mays, T. (2008). UP takes time to design. SAIDE Newsletter, 14(2). Retrieved August 7, 2008, from http://www.saide.org.za/resources/newsletters/vol_14_no.2_2008/Content/UP\%20Materi als.htm.

Meraka Institute (n.d.). Digital doorway project. Retrieved May 10, 2009, from, http://www.meraka.org.za/digitalDoorway.htm

Moll, I., \& Drew, S. (2008). Learning, a learning spiral and materials design in distance education. South African Institute for Distance Education (SAIDE). Work in progress.

Smythe, S., \& Witthaus, G. (1998). Supporting distance learners. A tutor's guide. South African Institute for Distance Education (SAIDE). Cape Town: Francolin Publishers.

South African Qualifications Authority (SAQA). (2005). Developing learning programmes for NQF-registered qualification and unit standards. Pretoria: SAQA.

Van der Bank, A.J. (2008). Case study of the ACE (Education Management). Internal document, Faculty of Education, University of Pretoria.

Welch, T., \& Reed, Y. (Eds.). (2005). Designing and delivering distance education: Quality criteria and case studies from South Africa. Johannesburg: NADEOSA. 
Woodley, A., \& Adrian Kirkwood. (1988). Evaluation in distance learning. In J. Jenkins (Ed.), Commonwealth co-operation in open learning: Background papers (pp. 291-98). London: Commonwealth Secretariat. 